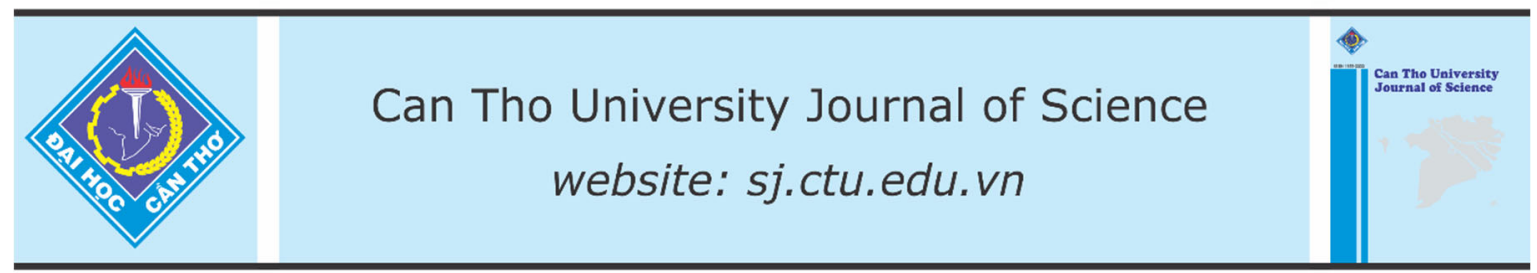

DOI: $10.22144 /$ ctu.jen.2019.002

\title{
Longan and rambutan in the Mekong Delta, Vietnam: A review of technologies to improve flowering and fruit setting
}

\author{
Tran Van Hau* and Tran Sy Hieu \\ Crop Science Department, College of Agriculture, Can Tho University, Vietnam \\ *Correspondence: Tran Van Hau (email:tvhau@ctu.edu.vn)
}

\section{Article info.}

Received 20 Mar 2018

Revised 08 Jun 2018

Accepted 29 Mar 2019

\section{Keywords}

'E-daw', floral induction, fruit set, 'Java', 'Rongrien', 'Tieu Da Bo', 'Xuong Com Vang'

\section{ABSTRACT}

This review was aimed to focus on the management techniques relating to flowering and fruit setting phenology of longan (Dimocarpus longan L.) and rambutan (Nephelium lappaceum L.). For longan, there are three common cultivars grown in the Mekong Delta, namely, 'Tieu Da Bo', 'Xuong Com Vang' and 'E-daw' (originated from Thailand). Their characteristics of flowering and fruit development are relatively different. The crop season of 'Tieu Da Bo' cultivar, from floral induction to harvesting, occurs within only 7.5-8.0 months, since the trees only need two leaf flushes before being able to be induced for flowering. As for the 'Xuong Com Vang' cultivar, three leaf flushes should be completed prior to the floral induction. Fruit development of ' $E$-daw' cultivar is relatively long, within 4.0-4.5 months. Therefore, the crop season of 'Xuong Com Vang' and 'E-daw' usually extends to almost 12 months. The most common flowering induction technique applied on longan is collar drenching of $\mathrm{KClO}_{3}$ alone ('E-daw') or in combination with branch girdling ('Tieu $\mathrm{Da}$ $B o$ ' and 'Xuong Com Vang'). $\mathrm{KClO}_{3}$ doses and time of application vary depending on the cultivar treated and crop season. For rambutan, the three popular cultivars grown in the Mekong Delta include 'Rongrien' (originated from Thailand), 'Nhan', and 'Java'. The latter is recently the most popular cultivar, and its crop season duration is about 9.5-10 months. The duration from fruit set to harvest is 14-16 weeks. Off-season floral induction on rambutan is implemented via the drainage of irrigation ditch combined with plastic mulching covering the growing bed. Another method is to spray Paclobutrazol onto the canopy when color of the third leafflush is light green (50-60 day-old). To improve fruit set, foliar application of 1Naphthaleneacetic acid (NAA) is recommended. The chemical, 30 ppm, can be sprayed to a few inflorescences possessing about $30 \%$ of blooming flower. In addition, immature fruit drop can also be reduced by the foliar application of NAA 20-40 ppm when fruit sized is 4-5 cm approximately.

Cited as: Hau, T.V. and Hieu, T.S., 2019. Longan and rambutan in the Mekong Delta, Vietnam: A review of technologies to improve flowering and fruit setting. Can Tho University Journal of Science. 11(1): 7-23. 


\section{LONGAN}

\subsection{Introduction}

In Vietnam, longan (Dimocarpus longan L.) is one of the most important fruit trees grown widely from the North to the South with an area of approximately $73,007.1$ ha distributed primarily in the Mekong Delta (MD) (more than $40 \%$ of the whole country area). Longan is grown mostly in Vinh Long province $(7,389.4$ ha), followed by Tien Giang (5,027.3 ha), Dong Thap (4,386.0 ha), and Ben Tre (3,626.0 ha) province ${ }^{1}$.

In the MD, there are various longan varieties cultivated, i.e. 'Thach Kiet', 'Thanh Nhan Bac Lieu', 'Giong' and 'Long' (Nguyen Minh Chau, personal comm.). The most popular longan cultivars include 'Tieu Da Bo', 'Xuong Com Vang', and 'E- daw' (originated from Thailand) (Fig. 1). 'Tieu Da Bo' is the primary cultivar in the MD, accounted for more than $70 \%$ of the total area thanks to many of its favorable characteristics, i.e. strong growth, small seed, high yield (20-30 ton/ha), and high profit which makes high demand. However, the area of 'Tieu Da Bo' is decreasing because of its high susceptibility to Witches' broom disease. 'Xuong Com Vang' is cultivated originally at the sandy coastal area of Vung Tau city. The cultivar was granted the highest prize in a fruit contest held by the Southern Fruit Research Institute (SOFRI, Vietnam) (Nguyen An De and Nguyen Van Hung, 2006). However, the variety was unable to be developed further due to low yield (10-15 ton/ha). Recently, area of 'Xuong Com Vang' tends to increase as a result of its resistance against Witches' broom disease.

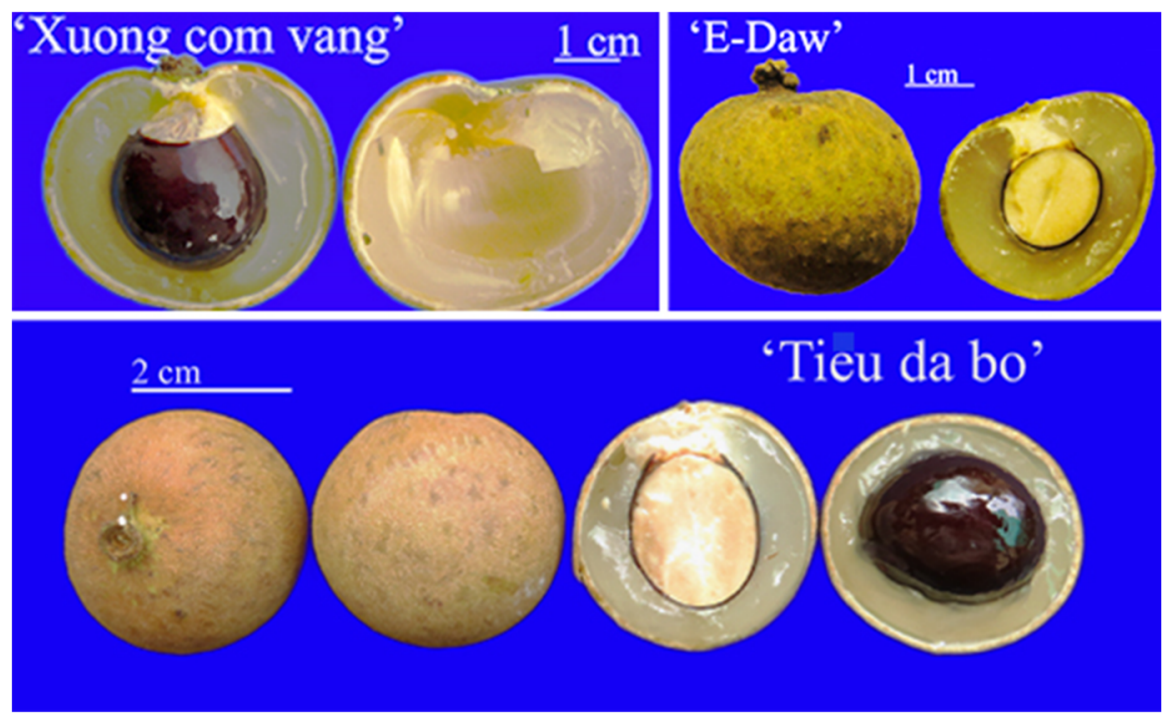

Fig. 1: The most popular longan cultivars grown in the MD, Vietnam

\subsection{Phenology of flowering and fruit development}

For longan, the duration from floral induction application to the emergence of flower buds is from 25-30 days ('Tieu Da Bo') to 30-35 days ('E-daw'). Fruit set occurs within 7 days. The duration of fruit development from fruit set until harvesting also changes depending on the cultivar, i.e. 90-105 days 'Tieu Da Bo' (Fig. 2), 84-86 days for 'Xuong Com Vang' (Fig. 3), and even longer (121-126 days) in the case of E-daw (Fig. 5, Table 1). The fruit development process is also different among the three cultivars. According to Mai Tran Ngoc Tieng
(1999), aril development is only started after the completion of seed development, hence the increase of fruit weight is corresponded to the development of aril weight whose commencement is relatively late. Fruit weight of 'Xuong Com Vang' starts to increase with the rise of aril weight at 56 days after fruit set (AFS) (Fig. 3a) and reaches to a maximum at 70 days AFS (Fig. 3b). Meanwhile, fruit weight of 'E-daw' increases greatly at 70 days (Fig. 5a) and becomes highest at 98 days AFS. Generally, longan fruit develops toward a simple curve, which is slow initially due to seed development, then much faster owing to the development of aril, and finally fruit maturity.

\footnotetext{
${ }^{1}$ General statistics office of Vietnam, 2016.
} 
Table 1: Leaf flush, flowering and fruit development of the three popular longan cultivars grown in the MD, Vietnam

\begin{tabular}{lrrl}
\hline Cultivar & $\begin{array}{r}\text { Duration from fruit } \\
\text { set to harvest (days) }\end{array}$ & $\begin{array}{r}\text { Duration from pruning } \\
\text { to harvest (days) }\end{array}$ & \multicolumn{1}{c}{ References } \\
\hline Tieu Da Bo & $90-105$ & $195-225$ & Tran Van Hau et al. $(2002)$ \\
\hline $\begin{array}{l}\text { Xuong Com } \\
\text { Vang }\end{array}$ & $84-86$ & $291 \begin{array}{l}\text { Tran Van Hau and Huynh Thanh Vu } \\
(2008) ; \text { Tran Van Hau and Phan Thi } \\
\text { Bich Tram (2012) }\end{array}$ \\
\hline E-daw & $121-126$ & 330 Tran Van Hau and Cao Sen (2012) \\
\hline
\end{tabular}

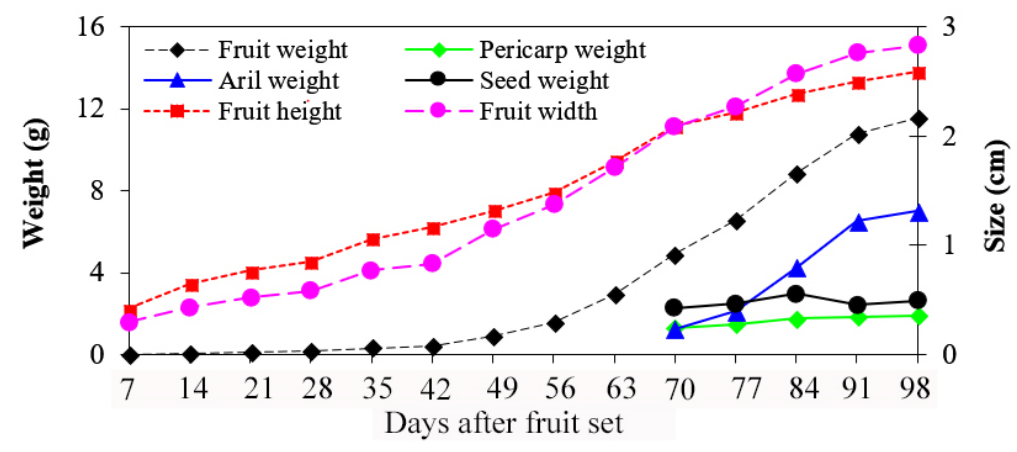

Fig. 2: Changes of weight and size of fruit components of longan cv. 'Tieu Da Bo', from fruit set to harvest (Tran Van Hau, unpubl.)
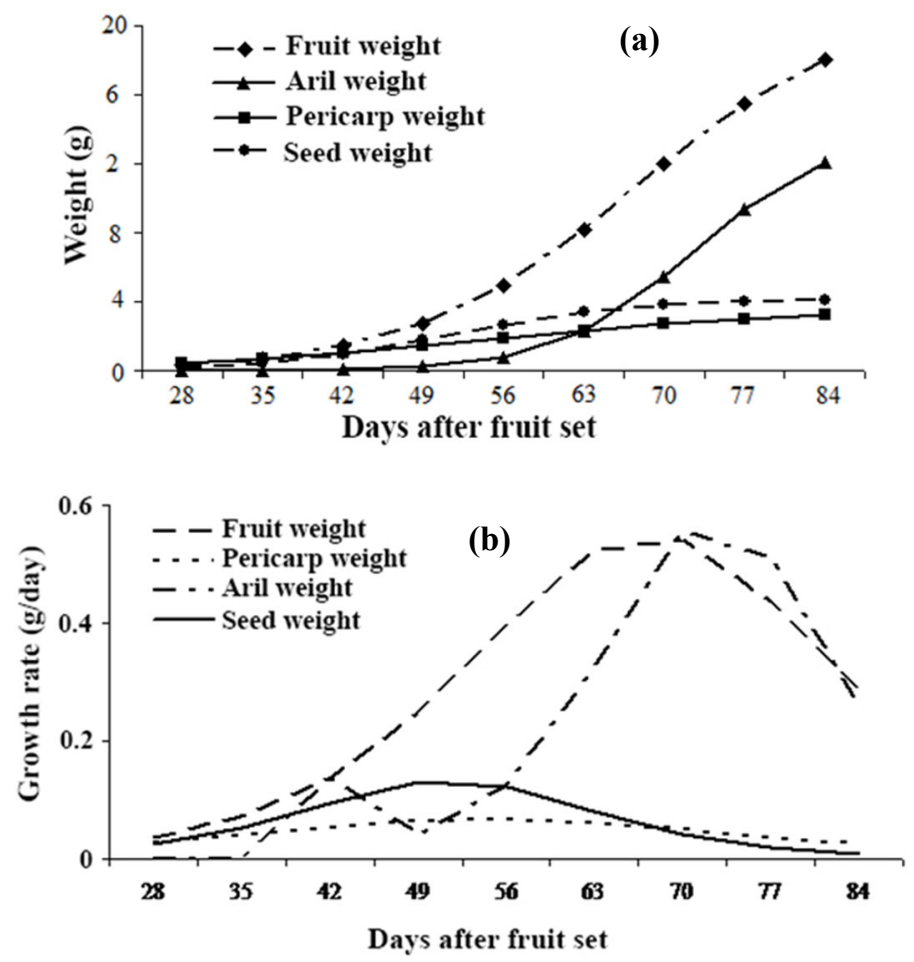

Fig. 3: Changes of weight (a) and growth rate (b) of fruit components of longan cv. 'Xuong Com Vang', from fruit set to harvest (Tran Van Hau and Phan Thi Bich Tram, 2012)

Note: Growth rate was calculated based on the growth equation proposed by Robertson (1908), viz. $Y^{\prime}=k x(a-x)$ with ' $x$ ' = weight of fruit components 

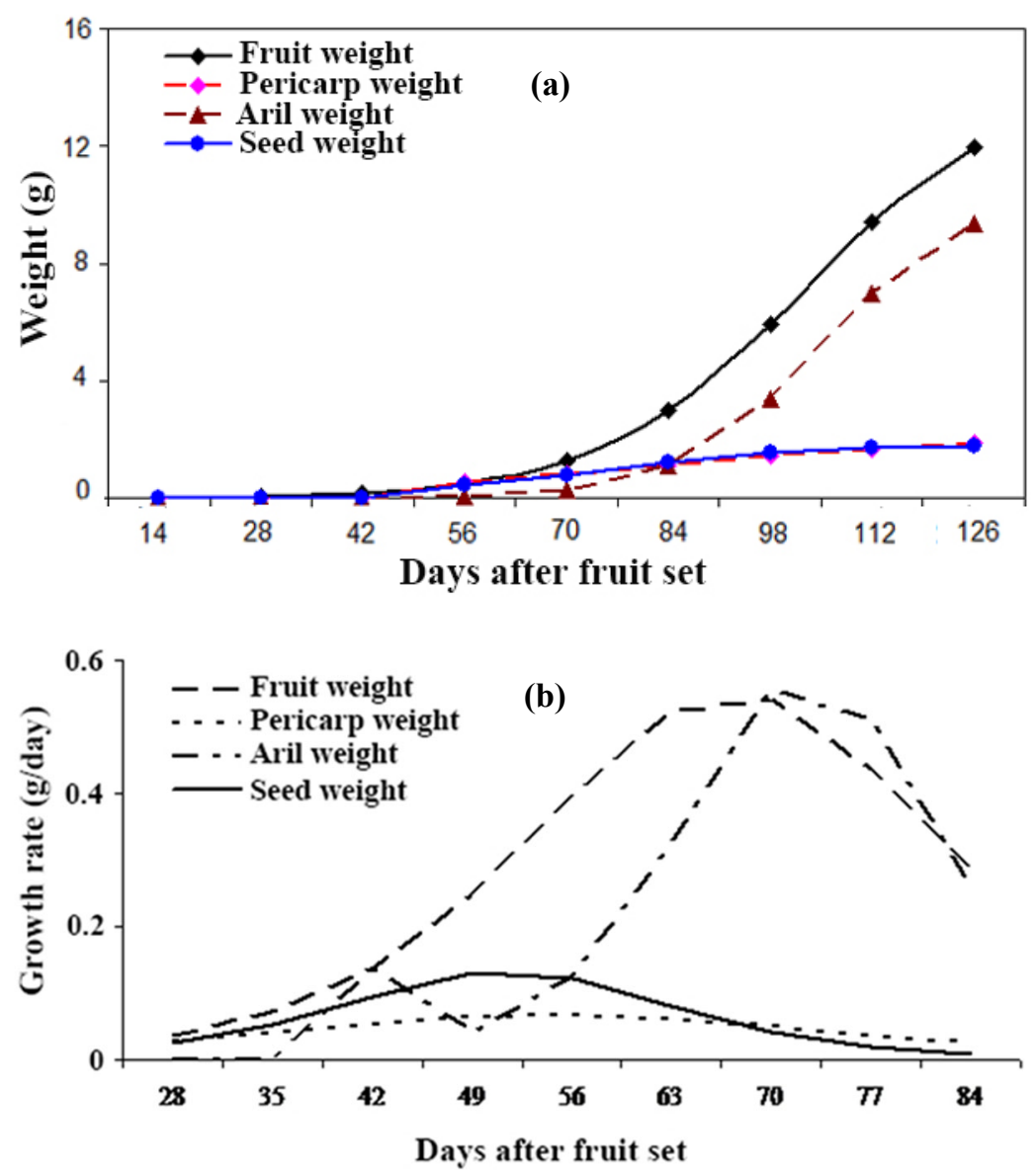

Fig. 4: Changes of weight (a) and growth rate (b) of fruit components of longan cv. 'Xuong Com Vang', from fruit set to harvest (Tran Van Hau and Phan Thi Bich Tram, 2012)

Note: Growth rate was calculated based on the growth equation proposed by Robertson (1908), viz. $Y^{\prime}=k x(a-x)$ with ' $x$ ' = weight of fruit components

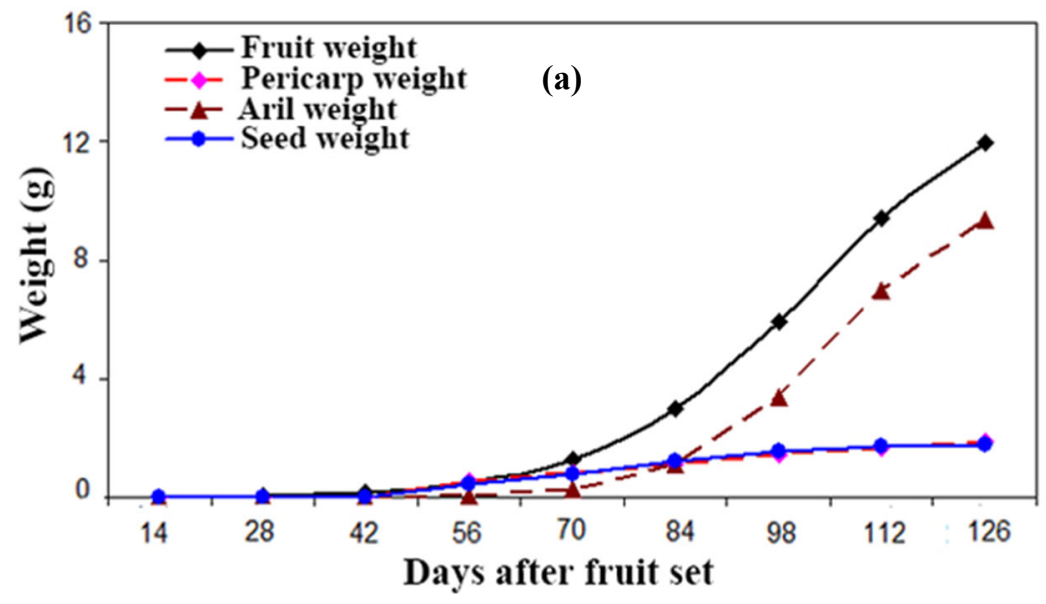




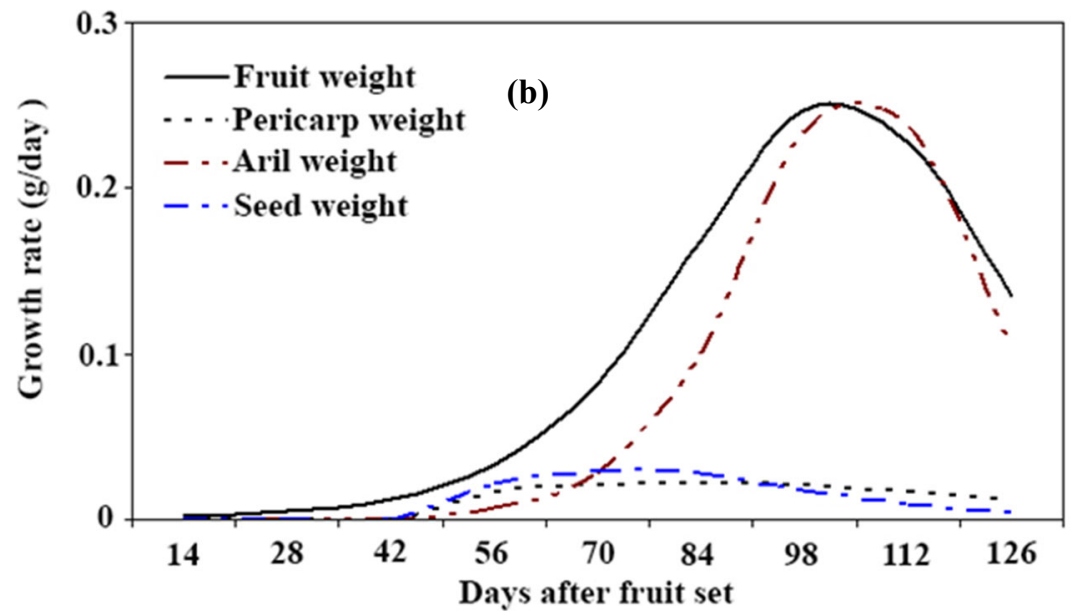

Fig. 5: Changes of weight (a) and growth rate (b) of fruit components of longan cv. 'E-daw', from fruit set to harvest (Tran Van Hau and Do Minh Huan, 2011)

Note: Growth rate was calculated based on the growth equation proposed by Robertson (1908), viz. $Y^{\prime}=k x(a-x)$ with ' $x$ ' = weight of fruit components

\subsection{Floral induction}

Logan flowers from terminal buds, hence inducing leaf flush after harvesting plays an important role to flowering and production of the next crop. For some common longan cultivars in the MD, growers usually manage to produce 2-3 leaf flushes (Table 2). Floral induction implicated after the completion of the third leaf flushes brings about more fruits per bunch than that undertaken when the tree only has two leaf flushes. However, the percentage of shoots accomplishing the third flush is low, and not concentrated. Therefore, it is very hard to foster leaf maturity by spraying of $0.5 \%$ MKP (Monopotassium phosphate), and to induce concentrated shooting by the foliar application of Potassium nitrate $(1 \%)$, respectively. Duration of the development of three leaf flushes, which is longer in rainy than in dry season, varies depending on the cultivar, from 90 days ('Tieu Da Bo') to 155 days ('E-daw') (Table 2).

Table 2: The effect of floral induction methods applied on the three popular longan cultivars grown in the Mekong Delta, Vietnam

\begin{tabular}{|c|c|c|c|c|c|c|}
\hline \multirow[b]{2}{*}{ Cultivar } & \multirow{2}{*}{$\begin{array}{r}\text { Leaf age } \\
\text { suitable for } \\
\text { floral in- } \\
\text { duction } \\
\text { (days) } \\
\end{array}$} & \multirow[b]{2}{*}{$\begin{array}{r}\text { No. } \\
\text { of } \\
\text { leaf } \\
\text { flush }\end{array}$} & \multirow{2}{*}{$\begin{array}{l}\text { Duration of } \\
\text { leaf flush } \\
\text { develop- } \\
\text { ment (days) }\end{array}$} & \multicolumn{2}{|c|}{ Method for floral induction } & \multirow[b]{2}{*}{ References } \\
\hline & & & & $\begin{array}{l}\text { Collar drenching } \\
\text { with } \mathrm{KClO}_{3}(\mathrm{~g} / \mathrm{m} \\
\text { canopy diameter) }\end{array}$ & $\begin{array}{r}\text { Girdling } \\
\text { width } \\
(\mathrm{mm})\end{array}$ & \\
\hline Tieu Da Bo & $30-35$ & 2 & $60-90$ & $30-50$ & $5-7$ & $\begin{array}{l}\text { Tran Van Hau et al. } \\
(2002)\end{array}$ \\
\hline $\begin{array}{l}\text { Xuong Com } \\
\text { Vang }\end{array}$ & 35 & $2-3$ & 164 & $30-40$ & $3-5$ & $\begin{array}{l}\text { Tran Van Hau and Le } \\
\text { Van Chan (2009) }\end{array}$ \\
\hline E-daw & $44-45$ & $2-3$ & 155 & $60-80$ & N/A & $\begin{array}{l}\text { Tran Van Hau and } \\
\text { Chau Ba Binh (2012) }\end{array}$ \\
\hline
\end{tabular}

Flowering of longan is driven by low temperature period, $15-22^{\circ} \mathrm{C}$ within $8-10$ weeks, and subsequently high temperature of spring which is favorable for the development of flower initiation (Nakasone and Paull, 1998). Low temperature and drought condition induce the production of Abscisic acid (ABA) in roots and shoots which involves in the flowering induction (Bower et al., 1989). Under the climate conditions of the MD, low temperature occurs from January to February, which is also dry period. Therefore, natural flower initiation is commenced in January-February, but starts to develop in April-May when rainy season begins. Thenceforth, the normal harvest time of longan in the MD is in August-September (Tran Van Hau, 2008). Because the price of longan in on-season is not high, growers has applied techniques using $\mathrm{KClO}_{3}$ to induce flowering in off-season to gain higher price. Explaining the mechanism of flowering induction caused by $\mathrm{KClO}_{3}$, Matsumoto et al. (2005) stated that the agent 
inhibits nitrate reductase activity in the treated longan trees. However, nitrogen as well as $\mathrm{C} / \mathrm{N}$ ratio in $\mathrm{KClO}_{3}$ treated and untreated trees were not significantly different. Furthermore, sodium chlorite and sodium hypochlorite were reported to be able to effectively decrease nitrate reductase activity and to induce flowering of longan trees as treated with $\mathrm{KClO}_{3}$ (Matsumoto et al., 2005). Therefore, the authors suggested that chlorate as well as its products after being reduced, i.e. chlorite and hypochlorite, may cause an alternative pathway for floral induction on longan besides their effects on the changes of nitrogen levels.

Methods for floral induction in the MD are different depending on cultivar and crop season (Fig. 6). Diczbalis and Drinnan (2007) reported that $\mathrm{KClO}_{3}$ is a powerful agent to induce flowering on longan. 'E-daw' cultivar needs higher dose of $\mathrm{KClO}_{3}$ than that required by 'Tieu Da Bo' and 'Xuong Com Vang', but it does not need to be combined with branch girdling (Table 2). For 'E-daw' longan grown in Thailand, Manochai et al. 1999 (cited by Manochai et al., 2005) reported that flowering percentage reached to $100 \%$ when potassium chlorate was applied at $8 \mathrm{~g}$ per square meter as collar drench (Table 3 ). The study was conducted in November, which is not the normal flowering time of longan in Thailand. In the $\mathrm{MD}$, higher $\mathrm{KClO}_{3}$ doses are required which is said to be due to higher annual average temperature. Moreover, the cultivar 'E-daw' only flowers under low temperature condition, thus it totally fails to flower in the natural condition of the MD, even when girdling is applied as the case of 'Tieu Da Bo' (Table 4). An explanation for the decrease in effectiveness of $\mathrm{KClO}_{3}$, according to Diczbalis and Drinnan (2007), is that the sites for producing flowering stimulus are reduced as a result of root hairs damages caused by $\mathrm{KClO}_{3}$ applications during the previous crops. Henceforth, in the subsequent crop seasons, higher thresholds of the flowering stimulus are required for the shoot to be able to shift from vegetative to reproductive stage.

Table 3: Flowering percentage (\%) of ' $\mathrm{E}$-daw' longan treated with $\mathrm{KClO}_{3}$ at different leaf ages in Thailand (Manochai et al., 1999, cited by Manochai et al., 2005)

\begin{tabular}{|c|c|c|c|}
\hline \multirow{2}{*}{$\begin{array}{l}\mathrm{KClO}_{3} \text { ap- } \\
\text { plication }\end{array}$} & \multirow[t]{2}{*}{ Leaf age } & \multicolumn{2}{|c|}{$\%$ flowering after application } \\
\hline & & 45 days & 60 days \\
\hline \multicolumn{2}{|c|}{ Control - no application } & 0.0 & 0.0 \\
\hline \multirow{3}{*}{$8 \mathrm{~g} / \mathrm{m}^{2}$} & Young leaves (less than 10 days) & 5.0 & 6.7 \\
\hline & Fully expanded leaves (20-25 days) & 30.0 & 61.7 \\
\hline & Mature leaves (40-45 days) & 85.0 & 100.0 \\
\hline
\end{tabular}

Table 4: Effect of $\mathrm{KClO}_{3}$ doses on flowering and fruit set of 'Tieu Da Bo' longan cultivar (Tran Van Hau et al., 2002)

\begin{tabular}{lrrrr}
\hline $\begin{array}{l}\mathrm{KClO}_{3} \text { dose } \\
\text { (g/m canopy diameter) }\end{array}$ & $\begin{array}{r}\text { Duration from } \mathrm{KClO}_{3} \text { ap- } \\
\text { plication to the emergence } \\
\text { of flower (days) }\end{array}$ & $\begin{array}{r}\text { Fruit set } \\
\text { duration } \\
\text { (days) }\end{array}$ & $\begin{array}{r}\text { Flowering per- } \\
\text { centage (\%) }\end{array}$ & $\begin{array}{r}\text { Inflorescence } \\
\text { length (cm) }\end{array}$ \\
\hline Control (girdling) & $23.6^{\mathrm{a}}$ & $13.4^{\mathrm{a}}$ & $80.4^{\mathrm{b}}$ & $20.1^{\mathrm{a}}$ \\
20 & $33.4^{\mathrm{b}}$ & $25.6^{\mathrm{b}}$ & $91.0^{\mathrm{d}}$ & $39.7^{\mathrm{b}}$ \\
40 & $33.2^{\mathrm{b}}$ & $27.6^{\mathrm{bc}}$ & $87.0^{\mathrm{c}}$ & $43.1^{\mathrm{b}}$ \\
60 & $34.0^{\mathrm{b}}$ & $28.8^{\mathrm{bc}}$ & $85.0^{\mathrm{c}}$ & $43.2^{\mathrm{b}}$ \\
80 & $35.2^{\mathrm{b}}$ & $29.8^{\mathrm{c}}$ & $76.1^{\mathrm{a}}$ & $47.0^{\mathrm{b}}$ \\
\hline $\mathrm{CV} \mathrm{( \% )}$ & 5.0 & 10.2 & 2.6 & 13.8 \\
$\mathrm{LSD}_{0.05}$ & 2.1 & 3.3 & 2.9 & 7.1 \\
\hline
\end{tabular}

Note: Within one column, numbers followed by identical letters are not significantly different at $\alpha=0.05$ as shown by Duncan multi-range test 

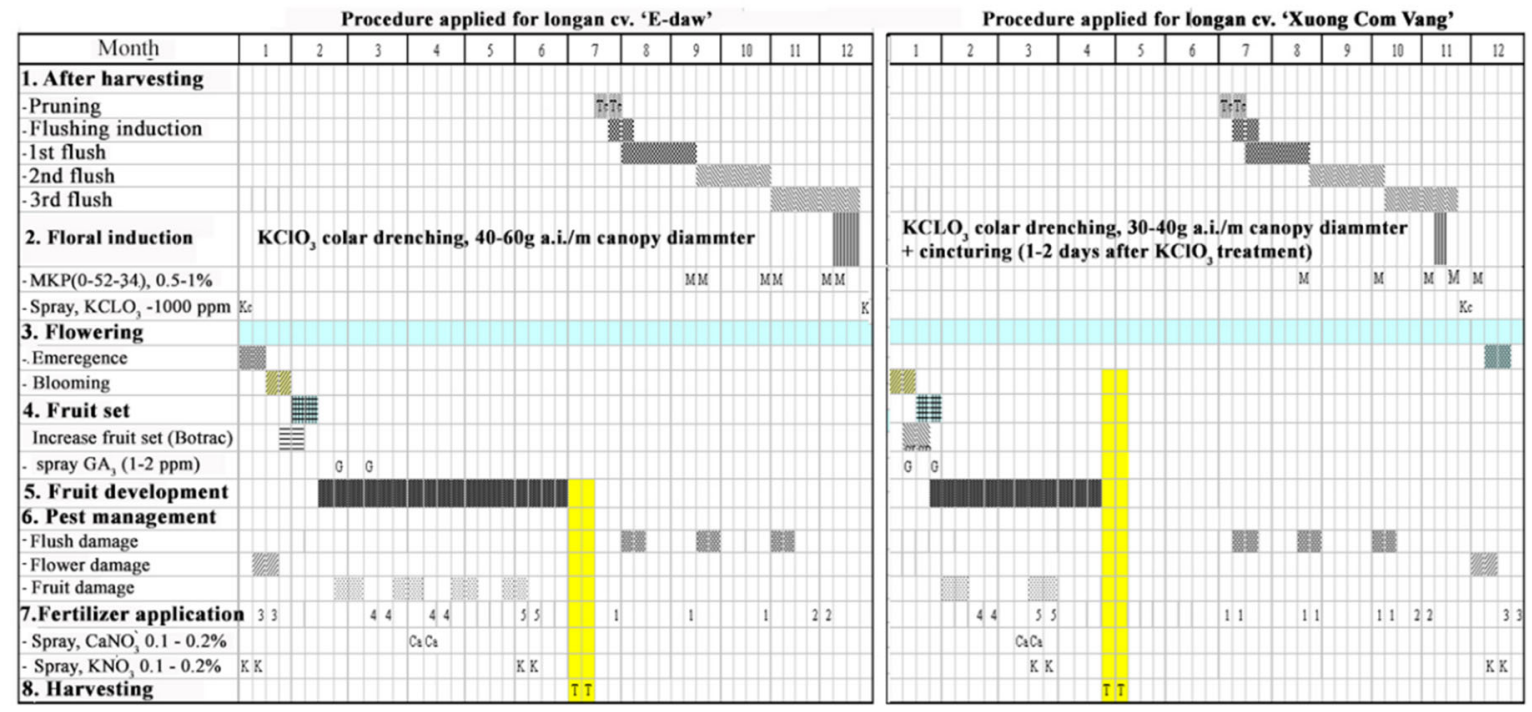

Fertilizer application:

1: Flushing induction (applied 5-7 days after pruning): combination of 20-20-15 and Urea at the ratio of 2:1

2: Flower bud initiation stage (2 weeks prior to $\mathrm{KClO}_{3}$ application): any fertilizer combination having the $\mathrm{N}-\mathrm{P}-\mathrm{K}$ ratio of $1: 2: 3$

3: Flower development stage (applied when inflorescence lenght is approx. 10 - 15cm): combination of NPK(15-15-15) and Urea at the ratio of 1:1

4.:Fruit development srage: NPK(20-20-15) or NPK (15-15-15)

5: Fruit maturation stage (30 days prior to harvesting): any fertilizer combination owing 2:2:3 NPK ratio

Fig. 6: Summarizing of production procedures for the two common longan cultivars, i.e. 'E-daw' and 'Xuong Com Vang', in the MD, Vietnam (Tran Van Hau, 2008)

Branch girdling is only applied on 'Xuong Com Vang' (Fig. 7a) and 'Tieu Da Bo' cultivar (Fig . 7b, Table 2). Because growth strength of 'Tieu Da Bo' is probably stronger than that of 'Xuong Com Vang', girdled width on branch of 'Tieu Da Bo' (5-
$7 \mathrm{~mm}$ ) is larger than that on 'Xuong Com Vang' (3$5 \mathrm{~mm})$. Only about $70-80 \%$ of branch in a tree should be girdled; a higher percentage will increase flowering percentage but reduce fruit size.

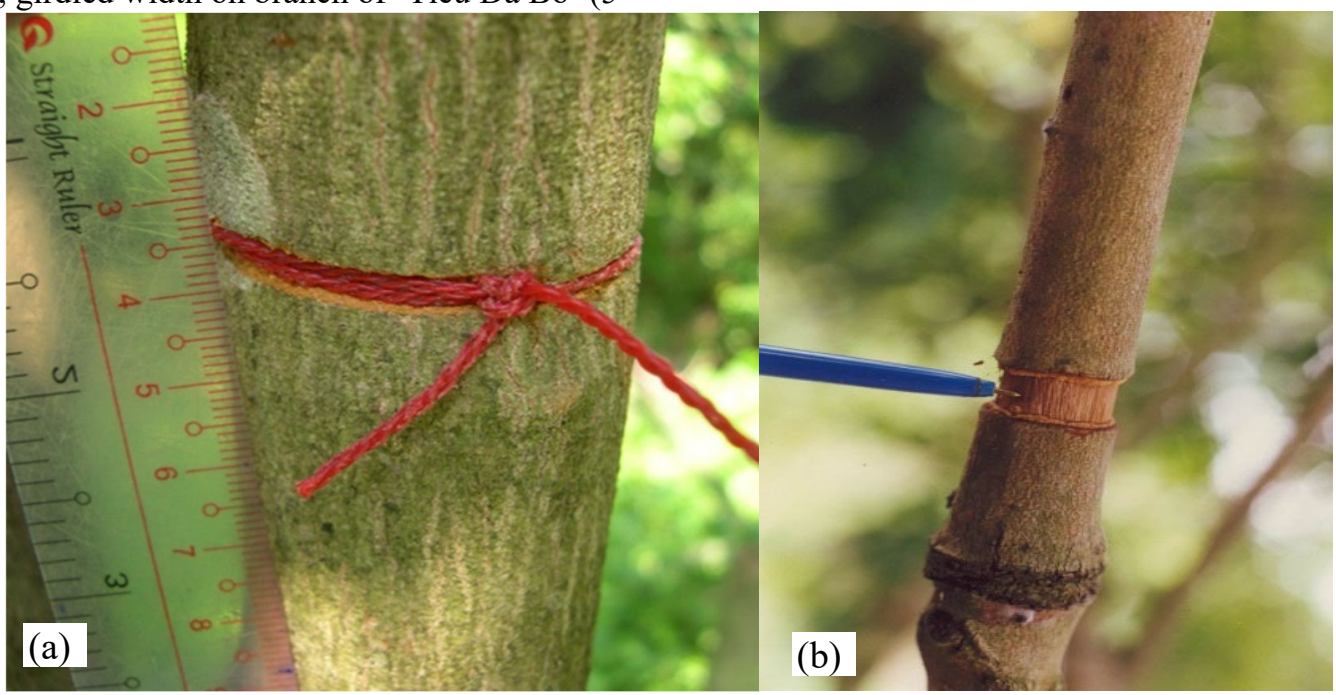

Fig. 7: Branch girdling applied as a floral induction treatment on (a) 'Xuong Com Vang' and (b) 'Tieu Da Bo' cultivar (Tran Van Hau and Le Van Chan, 2009) 
Leaf age at the time of floral induction is among the most important factors affecting flowering of longan. According to Hegele et al. (2001), although $\mathrm{KClO}_{3}$ is confirmed to be effective in year-round floral induction on longan, it exerts low or even no effect when floral induction is carried out while leaf is still young. The reason for such low effect was said to be due to the high auxin concentration in leaf. Leaf age suitable for floral induction is different depending on the cultivars (Table 2). 'Xuong Com Vang' is induced for flowering when its leaves are 35-day-old since emergence. Whereas in the case of 'E-daw', induction implemented when leaves are 44-day-old brings about high flowering percentage (Table 5). In Thailand, Manochai et al. (2005) also reported that flowering induction on 'E-daw' longan by collar drenching with $\mathrm{KClO}_{3}$ implemented when leaves reach to the "mature stage" (40-45 days) brings about high flowering rates observed at 45 $(85 \%)$ and 60 days $(100 \%)$ after $\mathrm{KClO}_{3}$ application (Table 3). In contrast, it is clear that the application conducted when leaves are young (10-30 day-old) results in low flowering percentage (Manochai et al., 2005;Tran Van Hau and Chau Ba Binh, 2012). Leaf age assessment is based on leaf color (Tran Van Hau and Chau Ba Binh, 2012) (Table 6). Generally, a favorable time for floral induction on longan is when leaf is turning from light to dark green (Table 6, Fig. 8).

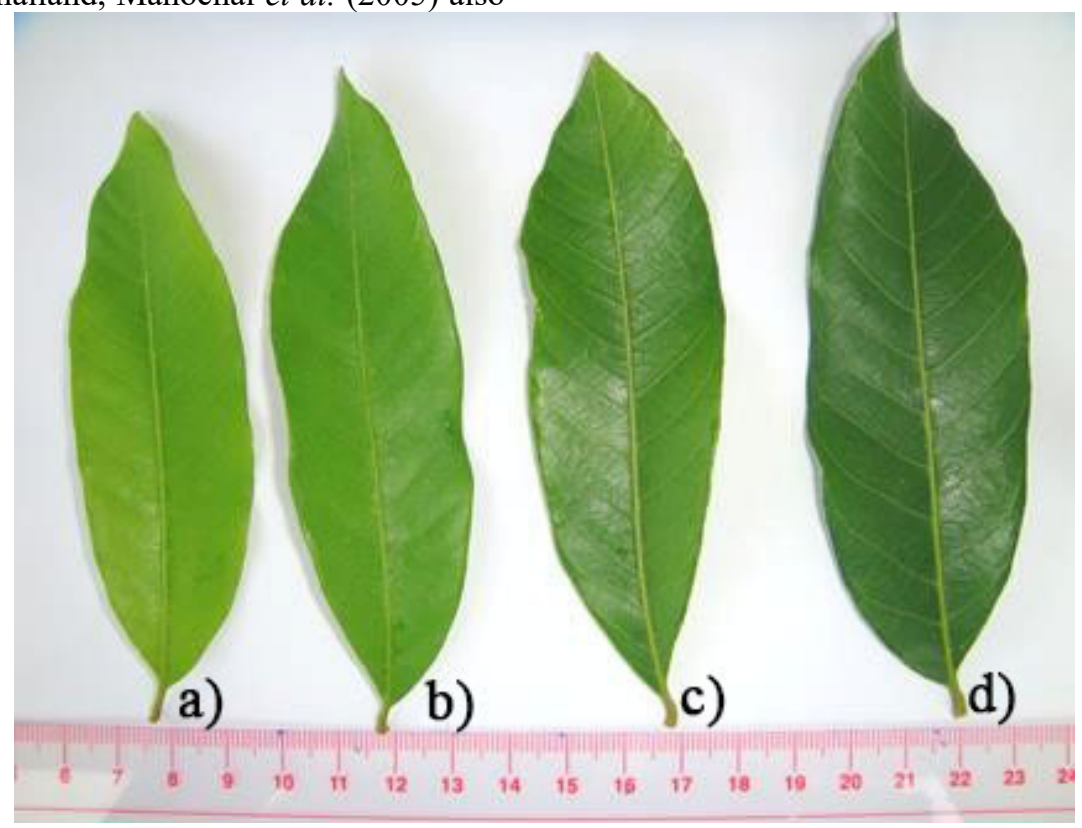

Fig. 8: Color of different leaf ages. Samples were collected one day prior to $\mathrm{KClO}_{3}$ treatment

30 days after emergence (DAE), b) 37 DAE, c) 44 DAE, d) 51 DAE (Tran Van Hau and Chau Ba Binh, 2012)

Table 5: Effect of leaf age at the time of $\mathrm{KClO}_{3}$ collar drenching on duration of flower bud emergence and flowering percentage of 5-year-old 'E-daw' longan trees (Tran Van Hau and Chau Ba Binh, 2012)

\begin{tabular}{lrr}
\hline $\begin{array}{l}\text { Leaf age } \\
\text { (Days after emergence) }\end{array}$ & $\begin{array}{r}\text { Duration from floral induction to } \\
\text { flower bud emergence (days) }\end{array}$ & Flowering percentage (\%) \\
\hline Control (untreated) & $\mathrm{N} / \mathrm{A}$ & $00.0^{\mathrm{d}}$ \\
30 days & $37.8^{\mathrm{a}}$ & $75.3^{\mathrm{c}}$ \\
37 days & $31.0^{\mathrm{b}}$ & $84.3^{\mathrm{b}}$ \\
4 days & $28.8^{\mathrm{b}}$ & $93.0^{\mathrm{a}}$ \\
51 days & $27.0^{\mathrm{c}}$ & $82.1^{\mathrm{b}}$ \\
Average & - & - \\
\hline F & $*$ & $*$ \\
CV (\%) & 6.9 & 5.0 \\
\hline
\end{tabular}

Note: Data was transformed into 'arcsine $\sqrt{\% x}$ prior to statistical analysis. Numbers followed by identical letters are not significantly different at $\alpha=0.05$ as shown by Duncan multi-range test; *: significant difference at $\alpha=0.05$ 
Table 6: Color difference of different ages of leaf sampled one day before $\mathrm{KClO}_{3}$ collar drenching on five-year-old 'E-daw' longan trees (Tran Van Hau and Chau Ba Binh, 2012)

\begin{tabular}{lrrrr}
\hline $\begin{array}{l}\text { Leaf age } \\
\text { (Days after emergence) }\end{array}$ & $\begin{array}{r}\text { Color difference } \\
(\Delta \mathbf{E})\end{array}$ & $\mathbf{L}^{*}$ & $\mathbf{a}^{\mathbf{*}}$ & $\mathbf{b}^{\mathbf{*}}$ \\
\hline 30 days & $51.1^{\mathrm{c}}$ & $36.4^{\mathrm{a}}$ & $-9.4^{\mathrm{b}}$ & $21.6^{\mathrm{a}}$ \\
37 days & $53.2^{\mathrm{bc}}$ & $34.6^{\mathrm{a}}$ & $-7.5^{\mathrm{b}}$ & $20.1^{\mathrm{a}}$ \\
44 days & $55.7^{\mathrm{ab}}$ & $29.9^{\mathrm{b}}$ & $-7.0^{\mathrm{ab}}$ & $12.4^{\mathrm{b}}$ \\
51 days & $58.6^{\mathrm{a}}$ & $26.8^{\mathrm{b}}$ & $-4.7^{\mathrm{a}}$ & $7.8^{\mathrm{b}}$ \\
\hline F & $*$ & $*$ & $*$ & $*$ \\
CV $(\%)$ & 4.5 & 7.3 & 26.7 & 22.8 \\
\hline
\end{tabular}

Note: Within one column, $t$ numbers followed by identical letters are not significantly different at $\alpha=0.05$ as shown by Duncan multi-range test $t$; *: significant difference at $\alpha=0.05$; Color and brightness in CIE color range: $+L$ : white, $-L$ : black, $+a$ : red, -a: green, $+b$ : yellow, -b: blue

In addition to the mentioned techniques, to achieve high flowering percentage on longan, it is necessary to apply fertilizer properly. In particular, while inducing leaf flush, nitrogen supply should not be exaggerated. In addition, irrigation ditch should be drained to create drought condition and reduce humidity at root zone, particularly during rain events. According to Diczbalis and Drinnan (2007), high leaf nitrogen content $(>1.7 \%)$ has a correlation with poor flowering $(0-25 \%$ of terminal buds flower). That suggests an overriding effect of leaf nitrogen content in longan flowering as compared with the other factors, e.g. dose of $\mathrm{KClO}_{3}$.

\subsection{Fruit set}

Fruit set and immature fruit drop are the most important factors affecting longan yield. According to Tran Van Hau (2016), fruit set of longan occurs within 7 days. In Thailand, the suitable temperature condition for fruit set is from $20-25^{\circ} \mathrm{C}$. Temperature higher than $40^{\circ} \mathrm{C}$ can cause damage on fruits and fruit drop (Tran Van Hau, 2016). Yaacob and Subhadrabandhu (1995) stated that high temperature and low humidity results in low fruit set and high fruit drop percentage. To improve yield of 'Tieu Da Bo', Bui Thi My Hong and Nguyen Vu Son (2008) suggested the foliar application of boric acid $100 \mathrm{ppm}$ or $\mathrm{GA}_{3} 5-10 \mathrm{ppm}$ twice, when flower inflorescence is about 5-10 cm length and 7 days after the first application. For 'Xuong Com Vang' cultivar, Bui Thi My Hong and Nguyen Vu Son (2008) recommended spraying 2 times with borax $2 \%$, specifically when inflorescence is $10 \mathrm{~cm}$ length and prior to blooming stage. In the case of 'Xuong Com Vang', to reduce immature fruit drop, Bui Thi My Hong et al. (2007) advised the spray of plant growth regulators (three times on a 7 day interval), i.e. IBA 5 ppm, NAA 10-20 ppm or BA 5-10 ppm when fruit diameter is about 4-5 $\mathrm{mm}$ ( 2 weeks AFS).

\section{RAMBUTAN}

\subsection{Introduction}

Rambutan (Nephelium lappaceum L.) is a tropical fruit and member of the Sapindaceae family closely related to the lychee and longan (Diczbalis, 2002). In Vietnam, the total rambutan area as reported by the general statistics office of Vietnam in 2015 was approximately 25,650.0 ha. The MD and Southeast region are the two main producers. In the $\mathrm{MD}$, there are $9,965.6$ ha of rambutan, mostly distributed in Ben Tre (5,694.0 ha), Vinh Long (2,445.7 ha), and Tien Giang province (811.1 ha). Yield of rambutan in the MD (21.0 tons/ha) is averagely higher than that of the whole country (15.7 tons/ha).

The three most popular rambutan cultivars grown in Vietnam are 'Java', 'Nhan', and 'Rongrien' (Fig. 9). The latter originated from Thailand. The most prevalent one is 'Java' because of its strong growth, higher yield (20-30 tons/ha) than 'Nhan'. Yield of 'Rongrien' cultivar is relatively identical to that of Java, but higher than the yield of Nhan'. In addition, its fruit quality is as good as that of 'Nhan', but much better than 'Java' in terms of sweetness, aril and skin thickness, and edible percentage (Dao Thi Be Bay et al., 2005). Recently growing area of 'Rongrien' is increasing thanks to its high quality, strong growth, and high benefit. However, the cultivar also has a disadvantage which is high percentage of splitted fruit (Tran Thi Bich Van and Le Bao Long, 2016). Rambutan grown in Vinh Long province is currently infected with Witches' broom disease as occurring on longan, but at a lower damage level, which is the primary constraint for rambutan development in the MD. 


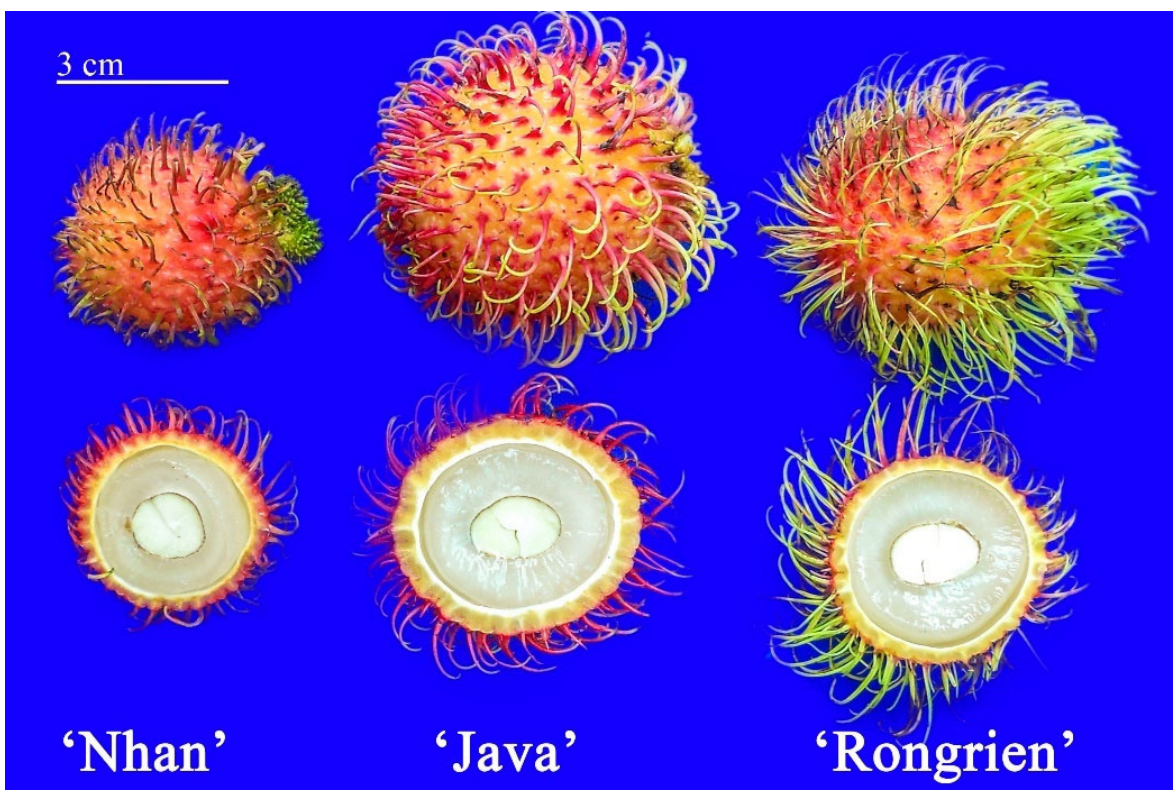

Fig. 9: The three most popular rambutan cultivars grown in the MD, Vietnam

\subsection{Phenology of flowering and fruit development}

Similar to longan, rambutan also flowers on terminal buds, therefore inducing leaf flush after harvesting is necessary. Rambutan is induced to produce 23 leaf flushes prior to floral induction. Total duration of one leaf flush is averagely 30-45 days, henceforth the total time for leaf flushes prior to flowering is about 3.0-4.5 months (Tran Van Hau and Chau Trung Duong, 2006). The process from floral induction to emergence of flower buds, blooming, and fruit set is presented in Table 7. The duration from application of Paclobutrazol (PBZ) to induce flowering until the creation and development of flower initiation (averagely 30-60 days) varies depending on many factors, such as drought condition, PBZ application (Tran Van Hau and Nguyen Viet Khoi, 2006). Inflorescence develops and commences blooming stage within 39 days. Immature fruit drop occurs primarily in two weeks AFS, and subsequently decreases and finishes at the $8^{\text {th }}$ week AFS. Fruit development peaks at the $10^{\text {th }}$ week AFS, corresponding with the creation and development of aril, until harvest.

Table 7: Duration of development stages, from floral induction to harvest, of rambutan induced for flowering by the foliar application of Paclobutrazol in combination with drainage of irrigation ditch and plastic mulching on growing bed (Tran Van Hau et al., 2006c)

\begin{tabular}{lr}
\hline Development stages & Duration (days) \\
\hline Floral induction - flower bud emergence & 43 \\
Flower bud emergence - blooming & 30 \\
Total duration of blooming & 9 \\
Fruit set - harvest & $98-112$ \\
\hline Total & 178 \\
\hline
\end{tabular}

Rambutan fruit development, from fruit set to harvest occurs within 16 weeks (Fig. 10). Similar to longan, rambutan fruits develop toward a simple curve started with fruit initiation after fruit set, then seed and aril development, and finally maturity. Fruit initiation occurs during the first five weeks of the fruit development process. Subsequently from the sixth week the seed is generated and recognizable from the seventh week. It develops until the twelfth week, and then keeps unchanged until harvest. Aril appears at the seventh week, then it proliferates since the $10^{\text {th }}$ week until harvest time (Fig. 10). At the $13^{\text {th }}$ week after fruit set, fruit skin turns to yellow as an indication of turning into maturity (Fig. 11); meanwhile, fruit weight still increases until ripening. Early harvesting when fruits only start to mature will reduce yield. 


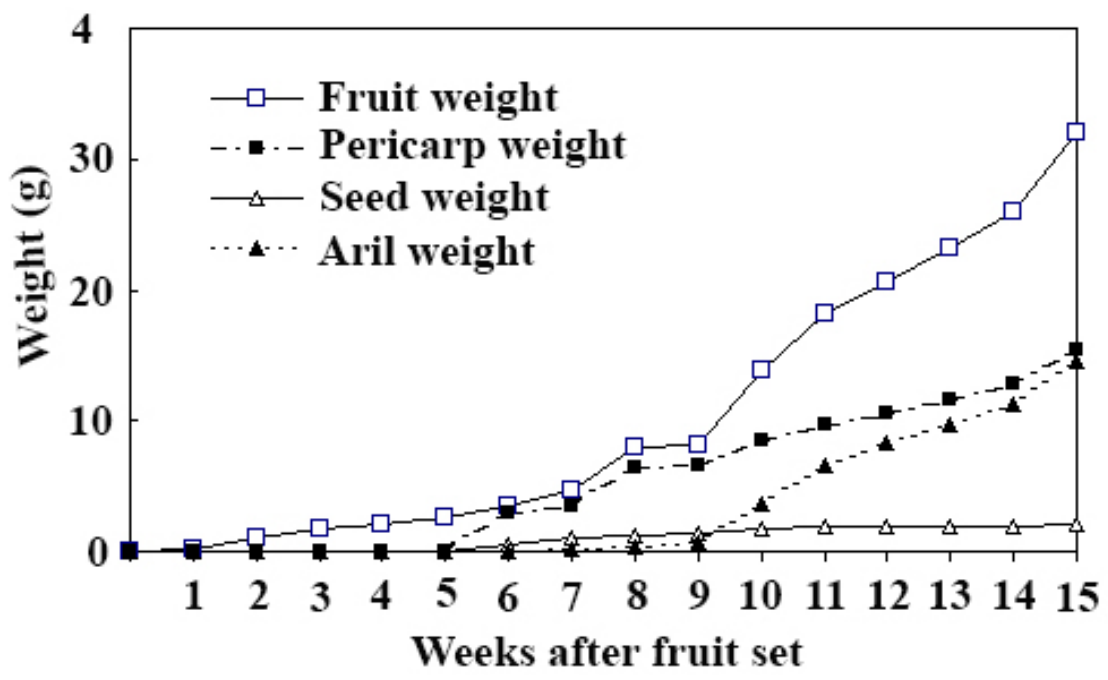

Fig. 10: Development and weight changes of 'Java' rambutan's fruit components (Tran Van Hau and Chau Trung Duong, 2006)

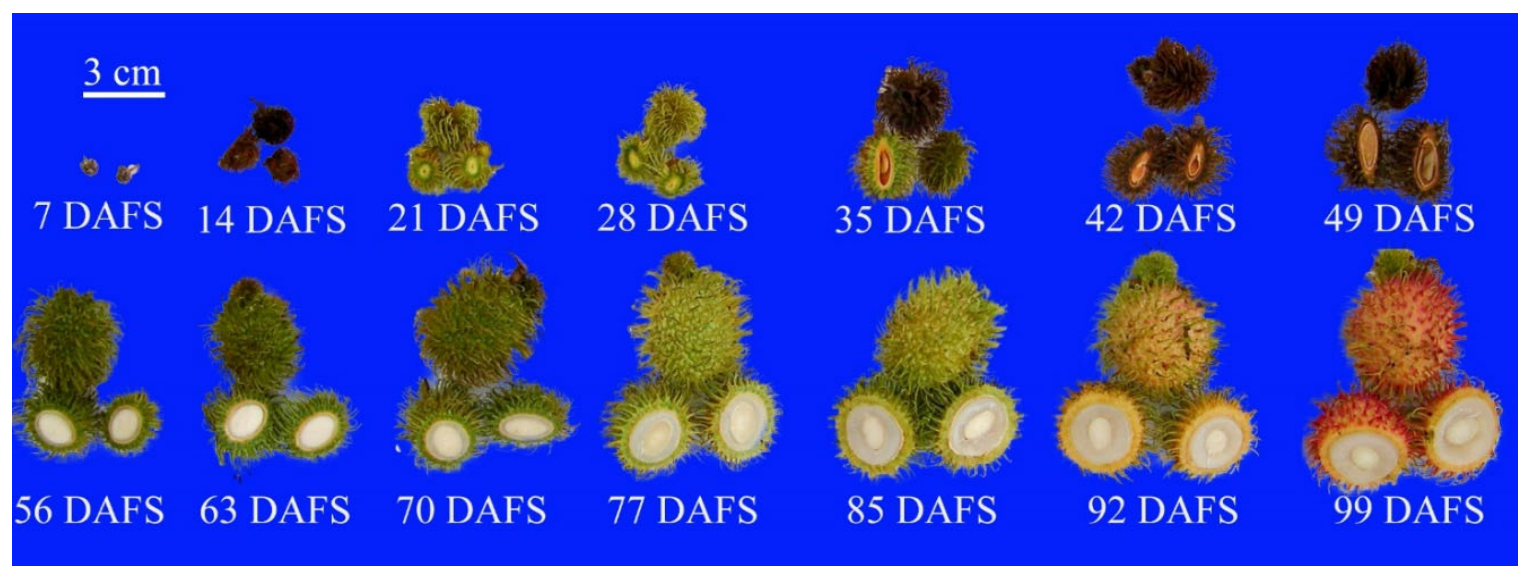

Fig. 11: Fruit development process of rambutan cv. 'Java', observed from 7 to 99 days after fruit set (Tran Van Hau and Chau Trung Duong, 2006)

Note: $D A F S=$ days after fruit set

During the fruit development process, fruit cracking (Fig. 12a) appears and causes significant reduction in fruit yield. In the MD, Tran Thi Bich Van and Le Bao Long (2016) reported that the phenomenon occurred at the start of fruit maturity, which is 12 weeks after fruit set (Fig. 12b). Subsequently, the percentage of fruit showing the phenomenon gradually increases until harvesting time. The phenomenon was linked to heavy rain events during the rapid growth of fruit flesh. Besides, another attributed cause of fruit cracking is that the affected fruits possesses thinner fruit skin and lower content of $\mathrm{Ca}^{2+}$ in it than these of the normal ones (Tran Thi Bich Van and Le Bao Long, 2016). Furthermore, strong correlations between cracking fruit percentage and $\mathrm{Ca}^{2+}$ content as well as fruit skin thickness were found. Therefore, Tran Thi Bich Van et al. (2016) suggested spraying fortnightly with $\mathrm{CaCl}_{2} 2.0-4.0 \%$ when fruits are at the $8^{\text {th }}$ week AFS. The treatment was reported to result in the increase the thickness of fruit skin and total $\mathrm{Ca}^{2+}$ content in it. Accordingly, it helps reduce fruit cracking percentage as well as ion leakage (\%) in comparison to these of the control-untreated treatment (Fig. 13). However, it is noticed that spraying of $\mathrm{CaCl}_{2} 4.0 \%$ reduced yield and TSS. 

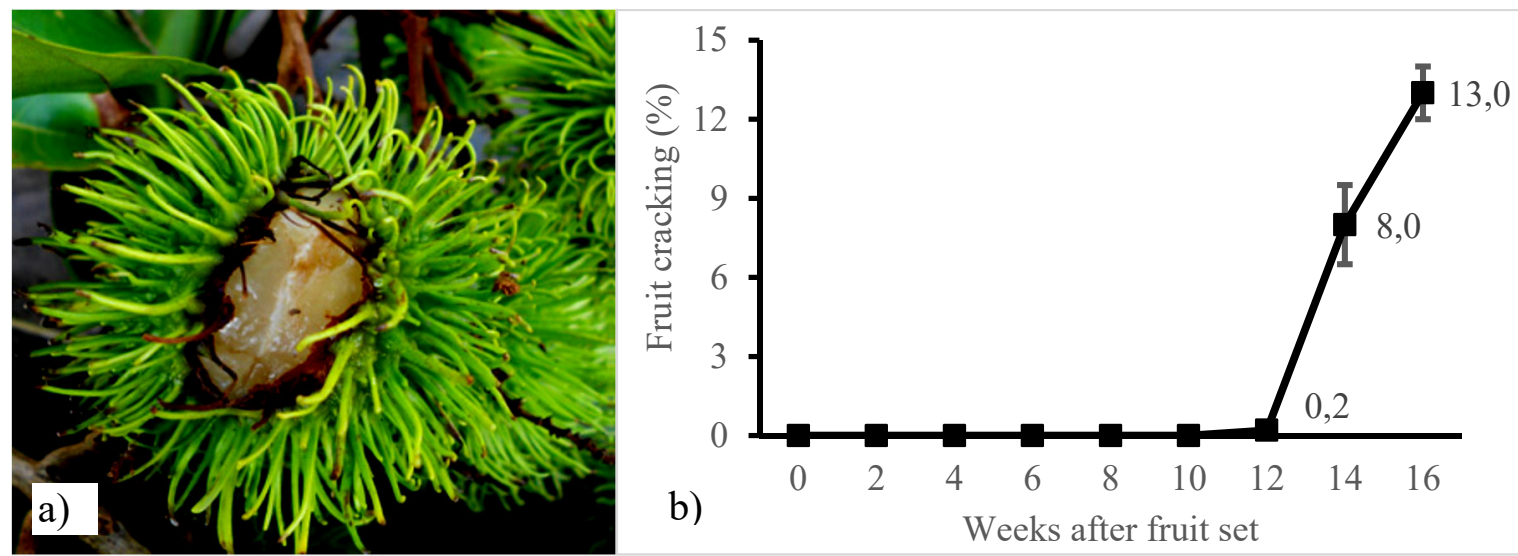

Fig. 12: Fruit cracking phenomenon occurring on rambutan cv. 'Rongrien' (Tran Thi Bich Van and Le Bao Long (2016). a) a fruit showing the fruit cracking phenomenon. b) appearance of the fruit cracking phenomenon during the fruit development

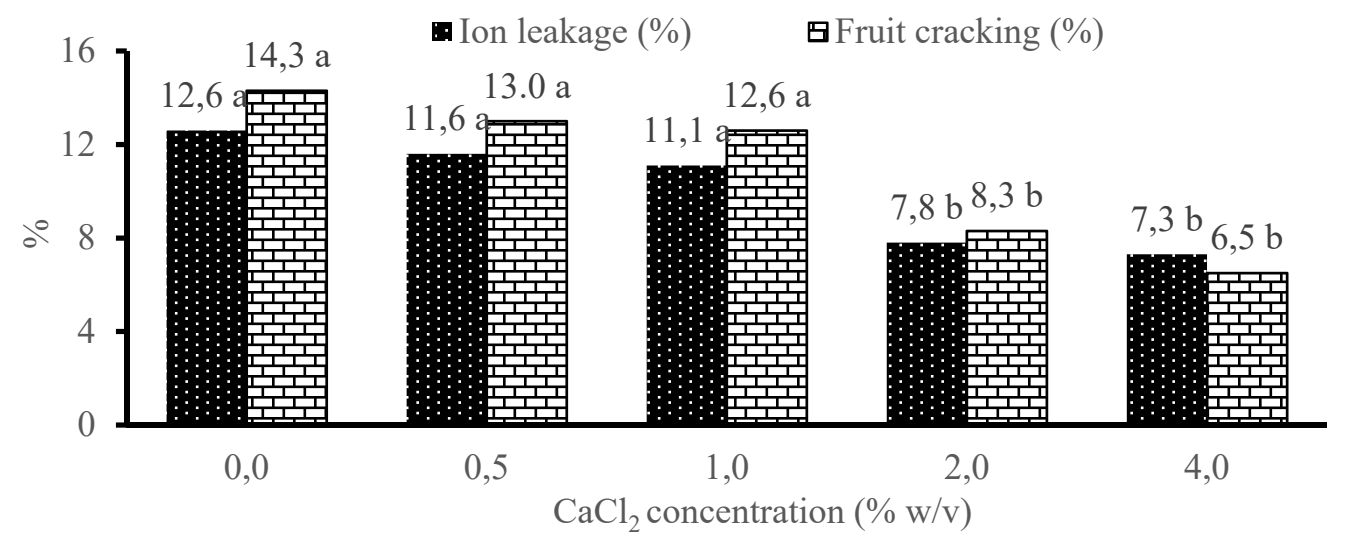

Fig. 13: Effect of $\mathrm{CaCl}_{2}$ on ion leakage (\%), fruit cracking (\%) of rambutan cv. 'Rongrien' grown in Phong Dien district, Can Tho city (Tran Thi Bich Van et al., 2016)

\subsection{Floral induction}

Although rambutan belongs to the same family of longan and lychee, it does not require low temperature condition for flowering and can adapt well to tropical climate with temperature ranging from 22 $30^{\circ} \mathrm{C}$ (Nakasone and Paull, 1998). A dry period of at least one month is essential to initiate rambutan flowering (Nakasone and Paull, 1998). Tindall et al. (1994) reported that in Malaysia rambutan can flower twice per year as there are two dry seasons. Growers in Cho Lach and Long Ho district drain irrigation ditch to create drought condition within 4061 days to induce flowering. It is reported that drainage duration correlates positively with flowering percentage $(\mathrm{r}=0.6, \mathrm{P}<0.05)$ (Tran Van Hau et al., 2006a). Nakasone and Paull (1998) also stated that the intensity of flowering appears to be closely associated with duration of water stress.

In the MD, rambutan flowers naturally in JanuaryFebruary which are cool and dry months of the year, and the harvest time is in July-August. Like other fruits, price of rambutan in on-season is very low, only equaled to $25-30 \%$ of that in off-seasons; thus, growers are applying techniques inducing off-season flowering to increase the price. Floral induction on rambutan can be implemented via drainage of irrigation channel to generate drought condition and applying plastic mulching alone or in combination with foliar spray of PBZ (Fig. 15).

Procedure for off-season floral induction on rambu$\tan$ in the MD is summarized in Table 8 and Fig. 14. Rambutan is induced for flowering when the tree completes three, or at least two leaf flushes. Ditch drainage or PBZ application is started when leaf color turn to light green, corresponding to 50-60 day-old since emergence. The tree will not flower if the induction is implemented while leaves are still young. Tran Van Hau et al. (2006a) reported that the content of gibberellins (GAs) like compounds in 
leaf decreases with leaf age and correlates negatively with flowering percentage $(\mathrm{r}=-0.9, \mathrm{P}<0.01)$. Similar to mango, Davenport et al. (2000) also stated that the older the leaf, the lower the content of GAs-like compounds. These authors explained that it is because of the transportation of GAs-like com- pound from leaf to the meristem. Fertilization to induce leaf flush prior to floral induction is also a factor affecting flowering. The amount of nitrogen used to induce leaf flush, particularly the last flush before floral induction, negatively correlates with flowering percentage $(\mathrm{r}=-0.7, \mathrm{P}<0.01)$.

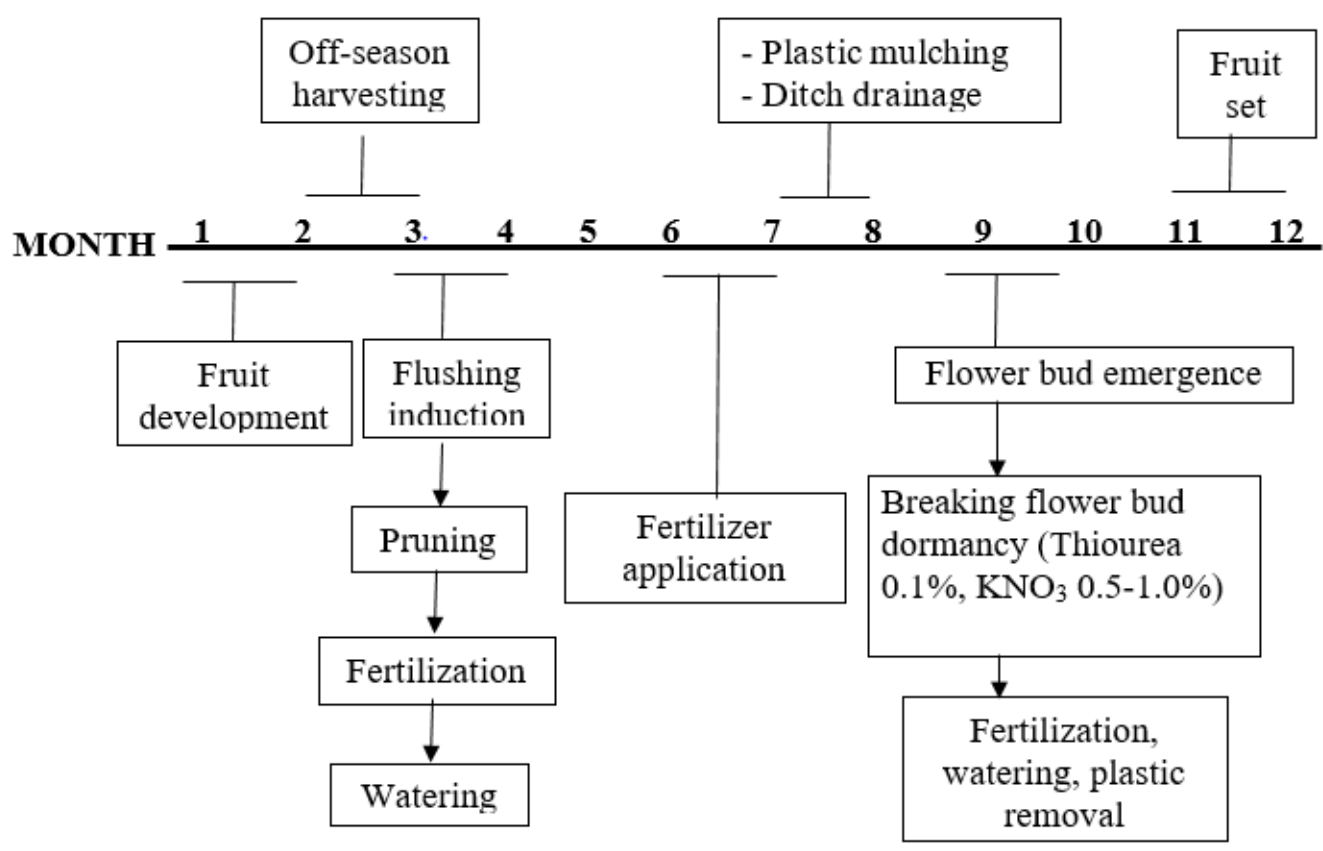

Fig. 14: Summarizing of a production procedure for rambutan cv. 'Java', in the Mekong Delta, Vietnam (Tran Van Hau, 2008)

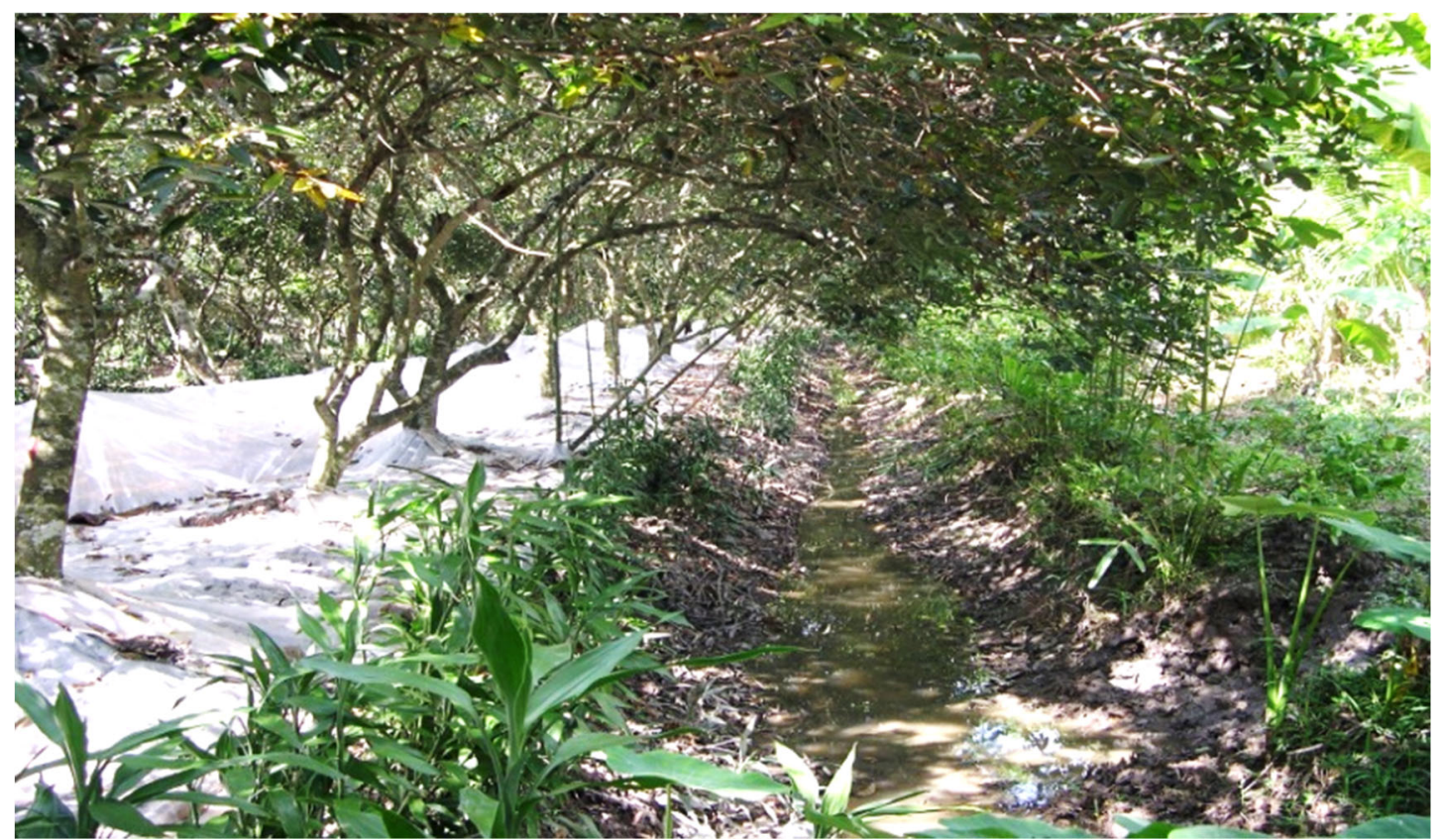

Fig. 15: Rambutan floral induction by mulching the raised bed in combination with drainage of irrigation ditch (Tran Van Hau et al., 2006c) 
Table 8: Methods for floral induction on 'Java' rambutan grown in the Mekong delta (Tran Van Hau et al., 2006b)

\begin{tabular}{ll}
\hline Method of floral induction & Value/characteristic \\
\hline Leaf age (days) & $50-60$ \\
Leaf color suitable for floral induction & Light green \\
Number of leaf flush prior to floral induction & $2-3$ \\
Concentration of PBZ (ppm) applied to the canopy & $400-600$ via foliar spray \\
Bed mulching combined with channel drainage (day) & $30-40$ \\
\hline
\end{tabular}

Since the prerequisite factor of flowering on rambutan is drought condition (water stress), the application of drainage of irrigation channel combined with air drying of raised bed and spell drought occurring in the rainy season also induce flowering up to $60 \%$ ca. (Table 9). However, the treatment is not steadily effective since the flowering percentage is low or even zero if there is rain. Such treatment can be improved by mulching the raised bed with plastic sheet
(Fig. 15), which can help increase flowering percentage up to $75 \%$. Besides treatments creating drought condition, foliar application of PBZ at 600 ppm can increase flowering percentage up to $80 \%$. When combined with plastic mulching, PBZ sprayed at $400 \mathrm{ppm}$ still results in high flowering percentage (Tran Van Hau et al., 2006c). Tindall et al. (1994) reported that the optimum PBZ concentration to induce flowering on 'Rongrien' cultivar is from 700-1,000 pm. A higher PBZ concentration will cause abnormal growth.

Table 9: Flowering percentage of 24-year-old 'Java' rambutan trees treated with Paclobutrazol as a single method or in combination with drainage of irrigation ditch, and mulching raised bed (Tran Van Hau et al., 2006c)

\begin{tabular}{|c|c|c|c|c|}
\hline \multirow{2}{*}{$\begin{array}{l}\text { Paclobutrazol concen- } \\
\text { tration (ppm) }\end{array}$} & \multicolumn{2}{|c|}{ Bed plastic mulching (MP) } & \multirow{2}{*}{ Mean } & \multirow{2}{*}{$\begin{array}{r}\text { Difference } \\
(\mathrm{A}-\mathrm{B}) \\
\end{array}$} \\
\hline & Practiced (A) & Not practiced (B) & & \\
\hline 0 & 75.1 & 61.5 & $68.3^{\mathrm{c}}$ & $13.6^{\mathrm{ns}}$ \\
\hline 200 & 84.7 & 61.4 & $73.1^{\mathrm{bc}}$ & $23.4^{*}$ \\
\hline 400 & 92.3 & 74.4 & $83.3^{\mathrm{ab}}$ & $17.9^{*}$ \\
\hline 600 & 92.0 & 81.1 & $86.6^{\mathrm{a}}$ & $10.9^{\text {ns }}$ \\
\hline Mean (PBZ) & 86.0 & 69.6 & - & $16.4^{* *}$ \\
\hline
\end{tabular}

$\mathrm{CV}(\%)=14.4$

$\mathrm{F}(\mathrm{MP})=*, \mathrm{LSD}_{0.05}=13.9$

$\mathrm{F}(\mathrm{PBZ})=* *, \mathrm{LSD}_{0.05}=9.8$

$\mathrm{F}(\mathrm{MP} * \mathrm{PBZ})=*, \mathrm{LSD}_{0.05}=19.7$

Note: Within one column, numbers followed by identical letters are not significantly different at $\alpha=0.05$ as shown by LSD test; $n s=$ non-significant deference at $\alpha=0.05 ; *$ ** significant difference at $\alpha=0.05$ and 0.01

In summary, to induce flowering on rambutan with high and stable flowering percentage in unfavorable conditions, some treatments to be applied include drainage of irrigation ditch, mulching raised bed with plastic sheet, and foliar application of PBZ at 400-600 ppm. In addition, to help flower buds generated concentratedly, it is necessary to spray thiourea at $0.1 \%$ when the emergence of flower buds is visible. Tindall et al. (1994) stated that flower buds only develop when they are spayed with nitrogen in the form of either potassium nitrate or thiourea two months after the foliar application of PBZ.

\subsection{Fruit set}

Fruit set is one of the most important factors affecting yield of rambutan. Fruit set percentage of 'Java' cultivar is relatively low, only $5-16 \%$; however, owing to the great number of hermaphrodite flowers
( $1,087 \pm 151$ flowers), the cultivar is still able to provide high yield (Tran Van Hau and Chau Trung Duong, 2006; Tran Van Hau et al., 2006b). According to Tindall et al. (1994), rambutan flowers are either male or hermaphrodite. The hermaphrodite flowers may be basically female with small stamens and non-dehiscent anthers or male possessing undeveloped stigmas. Failure of fertilization will result in abnormal fruits which are small/undeveloped, while the normal ones will increase and reach to the maximum size and weight at harvest stage (Fig. 16). That is likely because of the lack of pollens. During the 1990s, the incident severely reduced rambutan yield in Cho Lach district, Ben Tre province and Long Ho district, Vinh Long province. To improve fruit set, Bui Thanh Liem (1999) suggested the foliar application of NAA at 15-200 ppm, optimum at $30 \mathrm{ppm}$. That should only be sprayed on a few inflo- 
rescences around the canopy of the trees in the orchard. The suitable time for application is when blooming percentage is about $30 \%$. According to Bui Thanh Liem (1999), the treatment fosters the development of stamens of hermaphrodite flowers, hence expanding pollen supply and improving fruit set. Currently, the treatment has been largely applied by growers in Cho Lach and Long Ho district. The other method to increase fruit set is growing trees producing only male flowers, or grafting buds of male trees onto $5-10 \%$ of branches of trees producing hermaphrodite flowers (Hau, unpubl.).

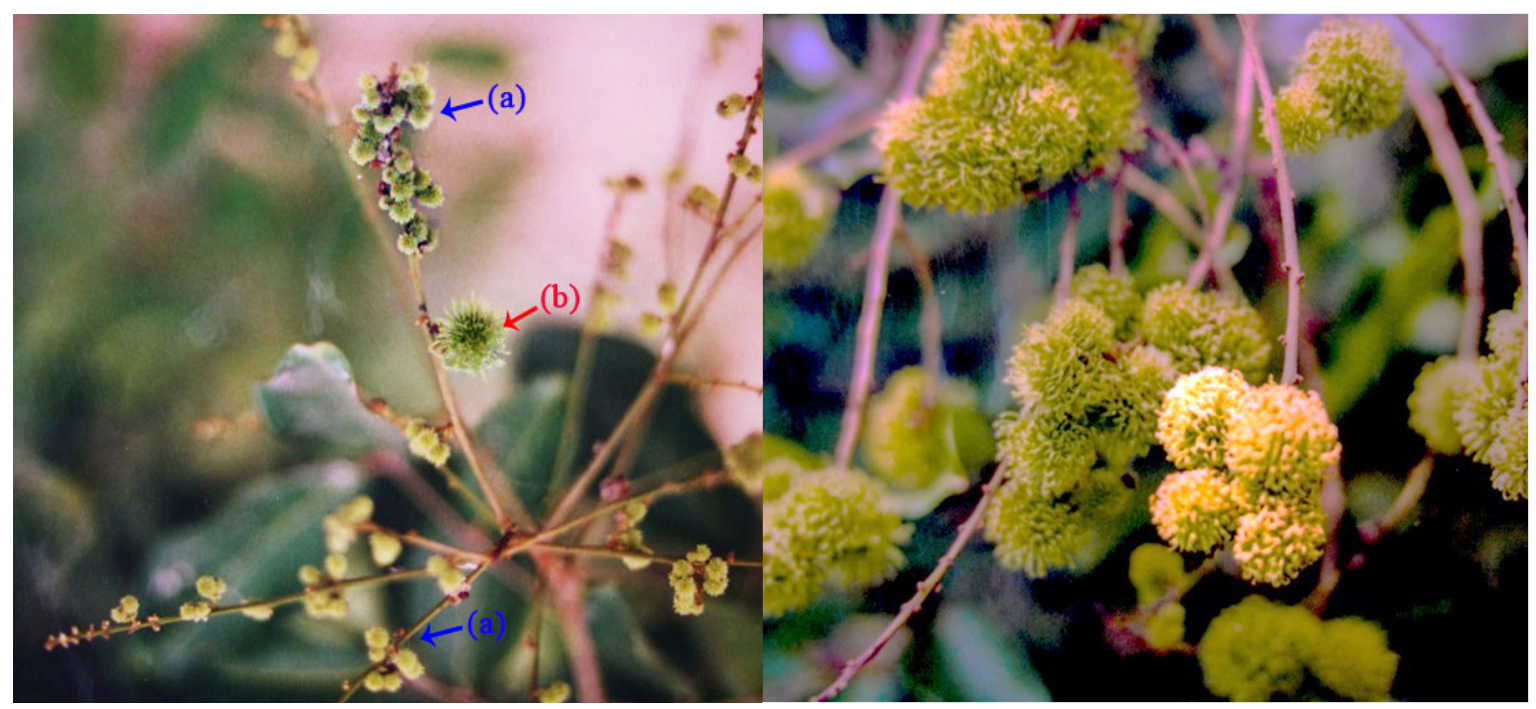

Fig. 16: Normal and abnormal fruits of rambutan cv. 'Java' grown in Cho Lach district, Ben Tre province. LEFT: (a) Abnormal fruit-small and undeveloped, (b) Normal fruit (Tran Van Hau, 2008); RIGHT: Abnormal fruits

To increase yield, application of techniques to reduce immature fruit drop is also important. Naturally, immature fruit drop occurs mainly at the third week after fruit set at about 50\% fruit of an inflorescence; subsequently it is decreased and ceased at the $8^{\text {th }}$ week after fruit set. (Tran Van Hau and Chau Trung Duong, 2006; Tran Van Hau et al., 2006b).
The remained fruits of a florescence are about $20 \%$. To reduce fruit drop occurring on 'Java' rambutan, Le Van Be and Le Van Hoa (2016) suggested the foliar application of NAA at 20-40 ppm when fruit size is about $4-5 \mathrm{~cm}$ (Table 10). The practice reduces significantly the fruit drop percentage as compared to that of the control treatment.

Table 10: Effect of foliar application of NAA on fruit drop percentage (\%) of rambutan cv. 'Java' (Le Van Be and Le Van Hoa, 2016)

\begin{tabular}{lcccc}
\hline \multirow{2}{*}{ Treatment } & \multicolumn{4}{c}{ Fruit drop (\%) } \\
\cline { 2 - 5 } & $\begin{array}{r}\text { 2 weeks after treat- } \\
\text { ment }\end{array}$ & $\begin{array}{r}\text { weeks after treat- } \\
\text { ment }\end{array}$ & weeks after treat- 8 weeks after treat- \\
ment & ment \\
\hline NAA 20 ppm & $46.2^{\mathrm{b}}$ & $61.6^{\mathrm{b}}$ & $70.0^{\mathrm{b}}$ & $70.8^{\mathrm{b}}$ \\
NAA 40 ppm & $38.2^{\mathrm{b}}$ & $64.4^{\mathrm{b}}$ & $70.1^{\mathrm{b}}$ & $70.4^{\mathrm{b}}$ \\
Control & $64.4^{\mathrm{a}}$ & $76.5^{\mathrm{a}}$ & $82.9^{\mathrm{a}}$ & $83.3^{\mathrm{a}}$ \\
\hline F & $* *$ & $* *$ & $* *$ & $* *$ \\
CV (\%) & 25.5 & 13.2 & 11.3 & 11.3 \\
\hline
\end{tabular}

Note: Within one column, numbers followed by identical letters are not significantly different at $\alpha=0.05$ as shown by LSD test; ** significant difference at $\alpha=0.01$

\section{CONCLUSIONS}

Both longan and rambutan flower from terminal buds. While longan requires low temperature condition to be able to flower, drought condition is necessary for the flowering of rambutan. It is exceptional that 'Tieu Da Bo' and 'E-daw' longan cultivars cannot flower naturally in the climate conditions of the
MD. The other cultivar, i.e. 'Xuong Com Vang', as well as rambutan can flower naturally in such conditions but at low flowering percentage, not concentrated, and low yield. To be able to sell fruits at high price, most of the rambutan and longan growers are applying techniques inducing year-round flowering. For 'E-daw', the most prevalent technique is collar drenching with $\mathrm{KClO}_{3}$. For 'Xuong Com Vang' and 
'Tieu Da Bo' cultivars, $\mathrm{KClO}_{3}$ collar drenching at different leaf ages can be integrated with branch girdling, 3-5 $\mathrm{mm}$ and 5-7 $\mathrm{mm}$ respectively.

For rambutan, flowering is induced by drainage of irrigation ditch, plastic mulching the raised bed alone or in combination with foliar spraying of PBZ at $400-600 \mathrm{ppm}$. The latter can be undertaken after the completion of the third leaf flush and when leaves have light green color. Pollen shortage is the primary cause of the abnormal fruits appearing during the fruit set. That eventually resulted in the reduction of fruit set of rambutan cv. 'Java'. Fruit set can be improved by spraying NAA 30 ppm directly onto a few inflorescences whose blooming percentage reaches to approximately $30 \%$. In addition, NAA, applied at 20-40 ppm when fruit size reaches to $4-5 \mathrm{~cm}$, can also be used to reduce immature fruit drop.

\section{REFERENCES}

Bower, J., Cutting, J., Lovatt, C., Blanke, M., 1989. Interaction of plant growth regulator and carbohydrate in flowering and fruit set. Proceedings of the International Symposium on the Culture of Subtropical and Tropical Fruits and Crops 275, 425-434.

Bui Thanh Liem, 1999. Effect of Naphthalene acetic acid on fruit set and preliminary studies on agents relating to floral induction of rambutan (Nephelium lappaceum L.) in Cho Lach district, Ben Tre province.Master thesis. Can Tho, Vietnam: Can Tho University (in Vietnamese with English abstract).

Bui Thi My Hong, Nguyen Minh Chau, Bui Trang Viet, 2007. Effect of plant growth regulators on immature fruit drop of 'Xuong Com Vang' longan. In. Research results of fruit and vegetable research in 2005 - 2006, SOFRI. Tien Giang, Vietnam: Agriculture publishing house HCM, (in Vietnamese).

Bui Thi My Hong, Nguyen Vu Son, 2008. Effect of boron on fruit set of 'Xuong Com Vang' longan. Research results on fruit and vegetable in 2006-2007 of SOFRI. In. Research results of fruit and vegetable research in 2006 - 2007, SOFRI. Tien Giang, Vietnam: Agriculture publishing house HCM (in Vietnamese).

Dao Thi Be Bay, Nguyen Huy Cuong, Le Minh Tam, Pham Ngoc Lieu, 2005. Clones selection of Rongrien rambutan variety. Research results of fruit and vegetable research in 2003 - 2004, SOFRI. In. Tieng Giang, Vietnam: Agriculture publishing house HCM, (in Vietnamese).

Davenport, T.L., Pearce, D.W., Rood, S.B., 2000. Correlation of endogenous gibberellic acid with initiation of mango shoot growth. Journal of plant growth regulation. 19 (4): 445-452.

Diczbalis, Y., 2002. Rambutan improving yield and quality. A report for the Rural Industries Research and Development Corporation. RIRDC. p. 9-69.
Diczbalis, Y., Drinnan, J.E., 2007. Floral Manipulation and Canopy Management in Longan and Rambutan: A Report for the Rural Industries Research and Development Corporation. Rural Industries Research and Development Corporation. 98 pp.

Hegele, M., Naphrom, D., Manochai, P., Chattrakul, A., Sruamsiri, P., Bangerth, F., 2001. Effect of leaf age on the response of flower induction and related hormonal changes in longan trees after $\mathrm{KClO}_{3}$ treatment. Proceedings of the IX International Symposium on Plant Bioregulators in Fruit Production 653, 41-49

Le Van Be, Le Van Hoa, 2016. Scientific basis for improving yield and quality of rambutan (Nephelium lappaceum L.). In: Nguyen Bao Ve, Hoa LV, (Eds.). Scientific basis for improving yield and quality of fruit trees in the Mekong Delta. Can Tho, Vietnam: Can Tho University Publishing House (in Vietnamese).

Mai Tran Ngoc Tieng, 1999. Producing small seed fruit of longan. Final report of a project funded by the department of science, technology and environment, Dong Thap province. 16 (in Vietnamese)

Manochai, P., Sruamsiri, P., Wiriya-Alongkorn, W., Naphrom, D., Hegele, M., Bangerth, F., 2005. Year around off season flower induction in longan (Dimocarpus longan, Lour.) trees by $\mathrm{KClO}_{3}$ applications: potentials and problems. Scientia horticulturae. 104 (4): $379-390$

Matsumoto, T., Tsumura, T., Zee, F., 2005. Exploring the mechanism of potassium chlorate-induced flowering in Dimocarpus longan. Proceedings of the International Symposium on Biotechnology of Temperate Fruit Crops and Tropical Species 738, 451-457

Nakasone, H.Y., Paull, R.E., 1998. Tropical fruits. CAB International. $464 \mathrm{pp}$.

Nguyen An De, Nguyen Van Hung, 2006. Selection of excellent individuals of longan groups and performances of some promising clones of Xuong Com Vang longan group in the condition of Southeast region. In. Research results on fruit and vegetable in 2004 - 2005 of SOFRI. Tien Giang, Vietnam: Agriculture publishing house HCM, (in Vietnamese).

Robertson, T.B., 1908. On the normal rate of growth of an individual, and its biochemical significance. Archiv für Entwicklungsmechanik der Organismen. 25(4): 581-614.

Tindall, H., U.G. Menini and A.J. Hodder, 1994. Rambutan cultivation. FAO Plant Production and Protection. Paper 121. 163 p.

Tran Thi Bich Van, Le Bao Long, 2016. Survey on the fruit cracking phenomenon in "Rongrien" rambutan (Nephelium lappaceum Linn) in Phong Dien district, Can Tho city. Can Tho University Journal of Science. 3: 210-217 (in Vietnamese).

Tran Thi Bich Van, Nguyen Bao Ve, Le Bao Long, 2016. Efect of foliar application of calcium chloride on the fruit cracking phenomemon and yield of rambutan cv. 'Rongrien' (Nephelium lappaceum Linn). Can Tho University Journal of Science. 45: 93-100 (in Vietnamese). 
Tran Van Hau, Nguyen Viet Khoi, Huynh Minh Phung, Phan Vo Nhu Ho Anh Thu, 2002. Effect of potassium chlorate on root damage, flowering, and fruit quality of 'Tieu Da Bo' longan. Can Tho University Journal of Science. 2002: 48-55 (in Vietnamese).

Tran Van Hau, Chau Trung Duong, 2006. Characteristics of rambutan (Nephelium lappaceum L.) grown at Can Tho city. Can Tho University Journal of Science. 6: 53-59 (in Vietnamese).

Tran Van Hau, Nguyen Viet Khoi, 2006. Effect of Paclobutrazol on year-round production of Java rambutan in Can Tho city. Collection of scientific studies relating to Agriculture and Applied Biiology, Can Tho University. Plant protection, Crop science and Plant genetics and breeding (2): 361-372 (in Vietnamese).

Tran Van Hau, Le Van Hoa, Nguyen Hoang Anh, 2006a. Relationship of endogenous gibberellin, $\mathrm{C} / \mathrm{N}$ ratio, and flowering of Java rambutan (Nephelium lappaceum L.). Can Tho University Journal of Science. (6): 60-68 (in Vietnamese).

Tran Van Hau, Nguyen Viet Khoi, Chau Trung Duong, 2006b. A surveyy on techniques relating to flowering induction on Java rambutan grown at Cho Lach district, Ben Tre province and Long Ho district, Vinh Long province. Collection of scientific studies relating to agriculture and applied biology, Can Tho University. 2 (Plant protection, Crop science and Plant genetics and breeding): 373-378 (in Vietnamese).

Tran Van Hau, Tran Van Khanh and Nguyen Thanh Nhan, 2006c. Effect of Paclobutrazol and plastic mulching on off-season flowering of Java rambutan in Can Tho city. Collection of scientific studies relating to agriculture and applied biology, Can Tho University. Plant protection, Crop science, Plant genetics and breeding (2): 353-360 (in Vietnamese).

Tran Van Hau, Huynh Thanh Vu, 2008. Biological characteristics of flowering and fruit development of 'Xuong Com Vang' longan (Dimocarpus longan Lour. var. Xuong Com Vang). Can Tho University Journal of Science. 2 (8): 29-76 (in Vietnamese).

Tran Van Hau, 2008. Flowering induction - a text book (Giáo trình môn xử lý ra hoa) Vietnam National University publishing house, Ho Chi Minh city, Vietnam (in Vienamese).
Tran Van Hau, Le Van Chan, 2009. Effect of potassium chlorate and branch cincturing on flowering and yield of 'Xuong Com Vang' longan (Dimocarpus longan Lour.). Can Tho University Journal of Science. 1 (11): 432-441 (in Vietnamese).

Tran Van Hau, Do Minh Huan, 2011. Investigation on growth characteristics, flowering, and fruit development of 'E-daw' longan (Dimocarpus longan Lour.) at Chau Thanh district, Dong Thap province. Can Tho University Journal of Science. 20: 129-183 (in Vietnamese).

Tran Van Hau, Phan Thi Bich Tram, 2012. Characteristics of flowering, fruit set, and development of ' $\mathrm{Xu}$ ong Com Vang' longan (Dimocarpus longan Lour.) at Chau Thanh district. Dong Thap province. Journal of Agriculture and Rural Development. 11/2012 (Special issue on "Sustainable development"): 72-78 (in Vietnamese).

Tran Van Hau, Cao Sen, 2012. Effect of Potassium Chlorate on flowering of 'E-daw' longan (Dimocarpus longan Lour.) in rainy season at Chau Thanh district, Dong Thap province. Proceedings of the the CAAB conference 2012-Sustainable agriculture developmen. Can Tho city, Vietnam, 106-120 (in Vietnamese).

Tran Van Hau, Chau Ba Binh, 2012. Effect of leaf age at the time of potassium chlorate application on off-season flowering of E-dor longan (Dimocarpus longan Lour.) at Chau Thanh district, Dong Thap province. Journal of Agriculture and Rural Development. (193): 43-50 (in Vietnamese) (in Vietnamese).

Tran Van Hau, 2016. Scientific basis for improving yield and quality of longan (Dimocarpus longan Lour). In: Nguyen Bao Ve, Le Van Hoa, eds. Scientific basis for improving yield and quality of fruit trees in the Mekong delta. Can Tho city, Vietam: Can Tho University Publishing House. (230-254 (in Vietnamese).

Yaacob, O., Subhadrabandhu, S., 1995. The production of economic fruits in South-East Asia. Oxford University Press. 